\title{
ANTIPLATELET ADEQUACY OF CYCLOPENTYL TRIAZOLOPYRIMIDINE VERSUS CLOPIDOGREL IN-PATIENTS WITH CORONARY HEART DISEASE
}

\author{
FERYAL HASHIM RADA* \\ Department of Clinical Laboratory Sciences, College of Pharmacy, Al-Nahrain University, Iraq. Email: fermsc33@yahoo.com
}

Received: 19 September 2018, Revised and Accepted: 22 October 2018

\begin{abstract}
Objective: Ticagrelor, cyclopentyl triazolopyrimidine drug, and Clopidogrel, second-generation thienopyridine drug are antiplatelet drugs indicated for the prevention of thrombotic events in patients with acute or chronic coronary syndromes. The aim of this study is to assess efficacy and safety outcomes of ticagrelor treatment versus Clopidogrel treatment in patients with stable coronary artery disease (stable angina) using maximal platelet aggregation percent (MPAP) method and platelet reactivity index percent (PRIP) method.
\end{abstract}

Methods: A total of 42 patients (27 male and 15 female), their ages ranging (48 \pm 8 ) years with stable angina enrolled from Ibn Albitar Center for Cardiac Surgery for this crossover study. After satisfying, the properties of inclusion criteria they screened for clopidogrel treatment 75 mg daily for 2 weeks than after 2 weeks periods of wash off they treated with ticagrelor 90 mg twice daily for another 2 weeks. Platelet reactivity was tested at baseline (before treatment), after 2 weeks treatment with clopidogrel and after another 2 weeks treatment with ticagrelor. Platelet reactivity measured by light transmittance aggregometry test and by vasodilator-stimulated phosphoprotein (VASP) phosphorylation test.

Results: The results of MPAP after 2 weeks treatment with clopidogrel or ticagrelor showed high significant reduction in platelet aggregation in patients with ticagrelor treatment as compared to clopidogrel treatment ( $30 \pm 6 \%$ vs. $44 \pm 8 \%$ ). As well, the results of PRIP using VASP-phosphorylation after 2 weeks treatment with clopidogrel or ticagrelor showed high significant reduction in platelet aggregation in patients with ticagrelor treatment as compared to clopidogrel treatment (22 $\pm 5 \%$ vs. $36 \pm 7 \%)$.

Conclusion: Treatment with ticagrelor produced a reduction in platelet reactivity consistent with the reduction in major adverse cardiovascular events and improved survival without increasing major bleeding.

Keywords: Clopidogrel, Ticagrelor, Major adverse cardiovascular events, Vasodilator-stimulated phosphoprotein.

(C) 2018 The Authors. Published by Innovare Academic Sciences Pvt Ltd. This is an open access article under the CC BY license (http://creativecommons. org/licenses/by/4. 0/) DOI: http://dx.doi.org/10.22159/ajpcr.2018.v11i12.29703

\section{INTRODUCTION}

Clopidogrel is a prodrug that required biotransformation into its active metabolite that irreversibly bound to platelet $\mathrm{P}_{2} \mathrm{Y}_{12}$ receptor for the platelet's lifespan (7-10) days and inhibits platelets activation and aggregation [1,2]. Inhibition of platelets aggregation using thienopyridine drug in addition to aspirin therapy amended the consequences of patients with acute coronary syndromes and patients with stents insertion as compared to patients with aspirin monotherapy [3].

Some patients after doing percutaneous coronary intervention and using clopidogrel drug with aspirin therapy may have high platelet reactivity (HPR) or may not response to clopidogrel; those patients may expose to higher rates of ischemic complication events [4].

Ticagrelor, a cyclopentyl triazolopyrimidine compound, is a nonthienopyridine drug and unlike thienopyridine drug, is reversibly bound to platelet $\mathrm{P}_{2} \mathrm{Y}_{12}$ receptor. Its inhibit platelet activation and aggregation with a rapid onset of action as compared to clopidogrel [5].

Many studies found that ticagrelor possess higher antiplatelet potency than clopidogrel, second-generation thienopyridine, and similar antiplatelet potency as prasugrel, third-generation thienopyridine. Therefore, ticagrelor can be used to reduce the risk of subsequent myocardial infarction and stent thrombosis [6,7]

As expected, due to the reversible binding of Ticagrelor with $\mathrm{P}_{2} \mathrm{Y}_{12}$ receptor this may lead to disperse its antiplatelet effect more rapidly with less bleeding [8].
The purpose of this crossover study was to assay platelets aggregation using two methods; maximal platelet aggregation percent (MPAP) method and platelet reactivity index percent (PRIP) method with two different treatments ticagrelor treatment or clopidogrel treatment in the same patients with stable angina at different times.

\section{METHODS}

Of 60 patients (43 males and 17 females) their ages ranging (50-60) years with stable angina enrolled from Ibn Albitar Center for Cardiac Surgery, only 42 patients ( 27 males and 15 females), their ages ranging $(48 \pm 8)$ years completed the designed period of this crossover study. The reasons for discontinuation-involved patients with normal levels of MPAP who are not need for using antiplatelet drugs, non-cooperative patients, and loss of follow-up.

The crossover study evaluated the same patients at different times in the presence and absence of the therapy under study with the presence of washout period for at least 2 weeks between two treatments.

The Institutional Ethics Committee in each study site approved patient selection and study protocol. Written informed consent was obtained from each patient.

Diagnoses made based on clinical symptoms, clinical biochemical tests (such as cardiac troponin I), and tests such as electrocardiogram, echocardiogram, and cardiac stress test. Exclusion criteria were involved patients with a history of acute coronary syndrome, bleeding, and concomitant therapy that has cytochrome P 3 A inhibitors or 
inducers, concomitant antithrombotic treatment, hemoglobin ( $\mathrm{Hb})$ level $<10 \mathrm{~g} / \mathrm{dl}$, liver disease, diabetes mellitus, renal failure, heart failure, and patients with neurological disorder such as epilepsy and tumors.

The patients treated with a maintenance dose of clopidogrel (Plavix, France) $75 \mathrm{mg}$ daily for 2 weeks. Then, after a washout period of 2 weeks, the patients treated with a maintenance dose of ticagrelor (Astrazeneca) $90 \mathrm{mg}$ twice daily for another 2 weeks.

Blood samples were collected in vacutainer tubes containing 3.2\% sodium citrate, after discarding first $3 \mathrm{ml}$ of free-flowing blood, at baseline (day 0 of treatment), after 2 weeks treatment with clopidogrel and after 2 weeks treatment with ticagrelorin the morning after $2 \mathrm{~h}$ of the last dose of the drug intake to measure the MPAP and the PRIP.

The MPAP was assay by measuring the inhibition of ADP $(20 \mu \mathrm{mol} / \mathrm{L})$ induced platelet aggregation of platelet-rich plasma which expressed as change in light transmittance from baseline, with platelet-poor plasma used as a reference and quantitated by light transmission aggregometry [8]

Whereas the PRI was assay by using vasodilator-stimulated phosphoprotein (VASP), platelet VASP-kit, which measured platelet P2Y12 receptor reactivity, and quantified by flow cytometry [9]

Platelet reactivity was expressed as a PRI and calculated as:

$$
\text { PRIP }=[\text { MFI }(\text { PGE1) }- \text { MFI }(\text { PGE1 + ADP }) / \text { MFI }(P G E 1)] \times 100 .
$$

Where MFI is mean fluorescence intensity, PGE1 is prostaglandin E1, and ADP is adenosine diphosphate. The (PRIP) ratio expressed as mean percentage of platelet reactivity and it is inversely correlated with antiplatelet drugs efficiency.

We used the following previously defined cut points of HPR associated with long-term ischemic event occurrence: $>59 \%(20 \mu \mathrm{mol} / \mathrm{L})$ ADPinduced maximal platelet aggregation [6] and $>50 \%$ PRI based on the VASP phosphorylation assay [9].

The primary safety endpoint was defined major bleeding as bleeding with clinically overt evidence or non, associated with a decrease in $\mathrm{Hb} \geq$ $5 \mathrm{~g} / \mathrm{dl}$, and minor bleeding as bleeding associated with a decrease in $\mathrm{Hb}$ of $<3 \mathrm{~g} / \mathrm{dl}$ [7]

All numerical data stratified as mean \pm standard deviation with $95 \%$ confidence interval. Comparisons of continuous variables were assessed by Student's t-test, $\mathrm{p}$ values of $0<0.05$ were regarded to be statistically significant. All statistical analyses were performed using Statistical Package for the Social Sciences version 18.0 for windows.

\section{RESULTS}

Baseline clinical data and demographic characteristics of the studied participants displayed in Table 1 . The platelet responsiveness to ADP stimulation, MPAP, after 2 weeks treatment with clopidogrel $75 \mathrm{mg}$ daily was highly appreciably lower as compared with its value at the baseline (before treatment).

Whereas the MPAP in the same patients after 2 weeks washout and after another 2 weeks treatment with ticagrelor $90 \mathrm{mg}$ twice daily was highly appreciably, lower as compared with MPAP value at the baseline or after 2 weeks treatment with clopidogrel 75 mg daily (Table 2 and Fig. 1).

As well, the high significant decrease was clarified in PRIP that measured by VASP-phosphorylation after 2 weeks treatment with clopidogrel $75 \mathrm{mg}$ daily as compared with its value at the baseline (before treatment)

In addition, the PRIP in the same patients after 2 weeks washout and after another 2 weeks treatment with ticagrelor $90 \mathrm{mg}$ twice daily was highly significantly decrease as compared with its value at the baseline or after 2 weeks treatment with clopidogrel $75 \mathrm{mg}$ daily (Table 2 and Fig. 1)

As noted in Fig. 2, the bar graph revealed the variations of MPAP and PRIP versus baseline after 2 weeks treatments, high variation achieved

Table 1: Baseline clinical data and demographic characteristics of the participants' patients

\begin{tabular}{ll}
\hline Variables & Patients \\
\hline Number $(\mathrm{n})$ & 42 \\
Gender (males, females) & $(27,15)$ \\
Age (years) & $48 \pm 8$ \\
WBC count $(1000 / \mathrm{mm})$ & $6.5 \pm 1.5$ \\
Platelet count $(1000 / \mathrm{mm})$ & $220 \pm 55$ \\
S. Creatinine $(\mu \mathrm{mol} / \mathrm{L})$ & $91.05 \pm 20.33$ \\
S. Uric acid $(\mu \mathrm{mol} / \mathrm{L})$ & $348 \pm 82.8$ \\
S.LDL-C $(\mathrm{mmol} / \mathrm{L})$ & $2.978 \pm 0.388$ \\
S.HDL-C $(\mathrm{mmol} / \mathrm{L})$ & $1.114 \pm 0.259$ \\
\hline
\end{tabular}

Data are presented as mean \pm SD (standard deviation) for continuous variables, $\mu \mathrm{mol} / \mathrm{L}$ : Micromole per liter, mmol/L: Millimole per liter, 1000/mm: Multiply by thousand cell per millimeter, Number (n): Sample size of the participants, S.LDL-C: Serum low-density lipoprotein cholesterol, S.HDL-C: Serum high-density lipoprotein cholesterol. SD: Standard deviation, WBC: White blood cell

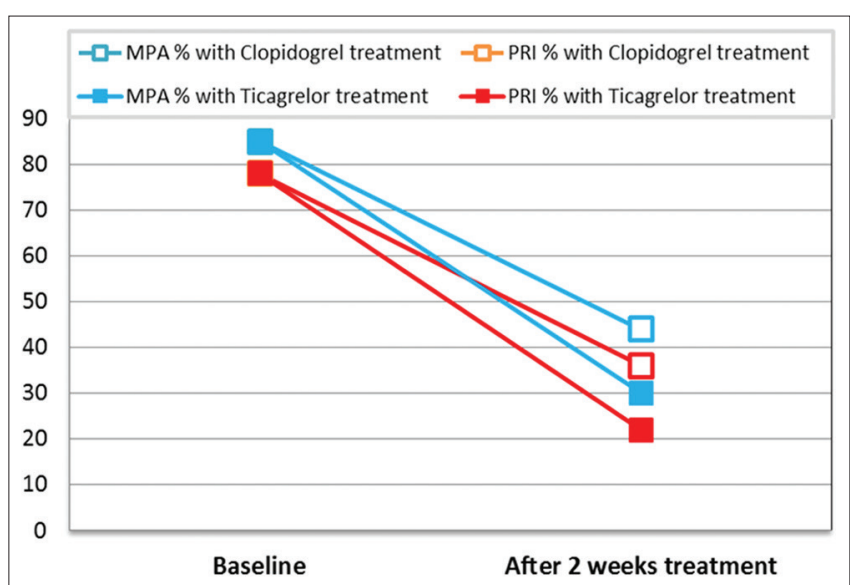

Fig. 1: Line chart demonstrates the effect of Clopidogrel $75 \mathrm{mg}$ daily treatment or ticagrelor $90 \mathrm{mg}$ twice daily treatment on the mean maximal platelet aggregation percent or the mean platelet reactivity index percent at baseline (before treatment) and after 2 weeks treatments, sample size $(n)=42$.

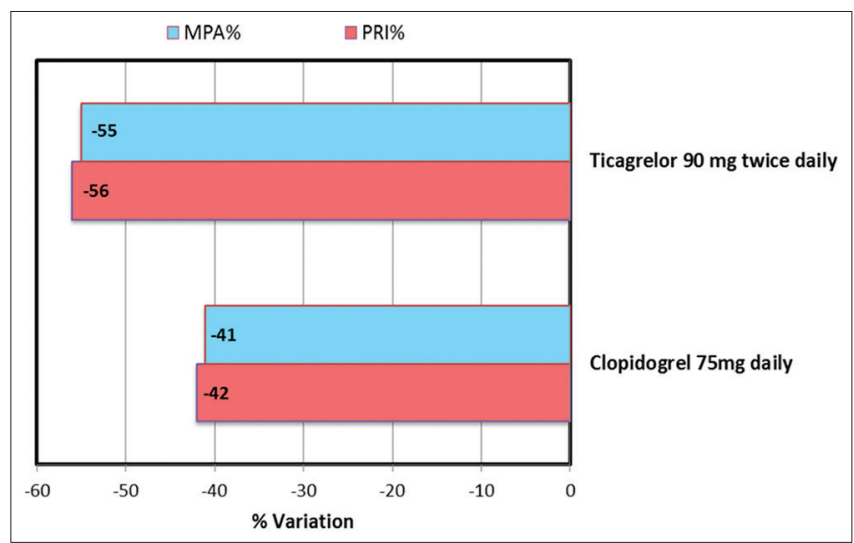

Fig. 2: Bar graph elucidated the percent variation of the mean maximal platelet aggregation percent and the mean platelet reactivity index percent versus baseline after 2 weeks treatment with clopidogrel or with ticagrelor, sample size $(n)=42$ 
Table 2: Comparison of differences in platelet aggregation response using MPAP method or PRIP method at baseline, after 2 weeks treatment with clopidogrel $75 \mathrm{mg}$ daily and after another 2 weeks treatment with ticagrelor $90 \mathrm{mg}$ twice daily

\begin{tabular}{llll}
\hline Variables & Baseline (before treatment) & Patients on clopidogrel 2 week & Patients on ticagrelor 2 week \\
\hline MPAP & $85 \% \pm 7.4$ & $44 \% \pm 8^{* *}$ & $30 \% \pm 6^{* *+}$ \\
PRIP & $78 \% \pm 6.5$ & $36 \% \pm 7^{* *}$ & $22 \% \pm 5^{* *+}$ \\
\hline
\end{tabular}

Data are presented as mean \pm SD (standard deviation) for continuous variables, sample size (n) $=42$ patients, ${ }^{* *}$ high significant decrease (p<0.001) as compared to baseline, †high significant decrease $(\mathrm{p}<0.001)$ as compared to MPAP or PRIP for patients on clopidogrel. PRIP: Platelet reactivity index percent, MRIP: Maximal platelet aggregation percent. SD: Standard deviation

in patients on ticagrelor treatment $90 \mathrm{mg}$ twice daily as compared to clopidogrel treatment 75 mg daily.

Analysis of adverse events showed that two minor bleeding occurred during ticagrelor treatment, and no bleeding occurred during clopidogrel treatment. As well, dyspnea episodes testified in five patients on ticagrelor therapy and three patients on clopidogrel therapy. On continuous treatment, dyspnea commonly ameliorated, especially when its intensity was mild to moderate.

Power analysis for the minimum detectable effect of clopidogrel treatment $75 \mathrm{mg}$ daily or ticagrelor treatment $90 \mathrm{mg}$ twice daily on MPAP and PRIP after 2 weeks of treatments are elucidated in Fig. 3.

There is $80 \%$ probability that a decrease of MPAP by $4.96 \%$ with clopidogrel treatment $75 \mathrm{mg}$ daily can be described and by $4.33 \%$ with ticagrelor treatment $90 \mathrm{mg}$ twice daily can also be described. As well, there is $80 \%$ probability that a decrease of PRIP by $4.74 \%$ with clopidogrel treatment $75 \mathrm{mg}$ daily can be sensed and by $4.07 \%$ with ticagrelor treatment $90 \mathrm{mg}$ twice daily can also be sensed.

\section{DISCUSSION}

The results of this study elucidated that treatment with the reversibly binding platelet $\mathrm{P}_{2} \mathrm{Y}_{12}$, ticagrelor, was greater inhibitor of platelet aggregation than clopidogrel and thereafter reduced major ischemic events by reducing cardiovascular death, myocardial infarction, and stroke without significantly increasing major bleeding, these results are consistent with the PLATO overall results [10,11].

Likewise, to the other study $[12,13]$, the current study showed that ticagrelor treatment may associate with adverse events such as bradycardia and dyspnea, which may be related to the inhibitory effect of ticagrelor on adenosine reuptake by red blood cells.

Cannon et al. reported that the patients intended for non-invasive management and non-ST elevation coronary artery syndrome, exhibit higher rate of long-term adverse events than did those intended for invasive management [14]. As well, the patients who managed without revascularization usually have more comorbidity, higher risk of bleeding, and inferior outcome than patients who are revascularized [15].

Cannon et al. revealed that in contrast to clopidogrel treatment, ticagrelor treatment throughout the $1^{\text {st }}$ week produced an additional ventricular gap that detected by Holter instrument [13]. Many studies reported a link between patients' resistance to clopidogrel and major adverse cardiovascular events (MACE) [16-18].

VASP is a critical protein that is involved in the remodeling of the actin cytoskeleton, while in platelets it has a role in regulating adhesive events that are associated with platelet aggregation [19].

Flow cytometric assessment of VASP phosphorylation and the Verify Now $\mathrm{P}_{2} \mathrm{Y}_{12}$ assay has the advantage of measuring $\mathrm{P}_{2} \mathrm{Y}_{12}$ function directly, whereas ADP-induced platelet aggregation (light transmission) is influenced by $\mathrm{P}_{2} \mathrm{Y}_{12}$ receptor and other receptor $\left(\mathrm{P}_{2} \mathrm{Y}_{1}\right.$ receptor) which activate platelet and promoting platelet aggregation [20].

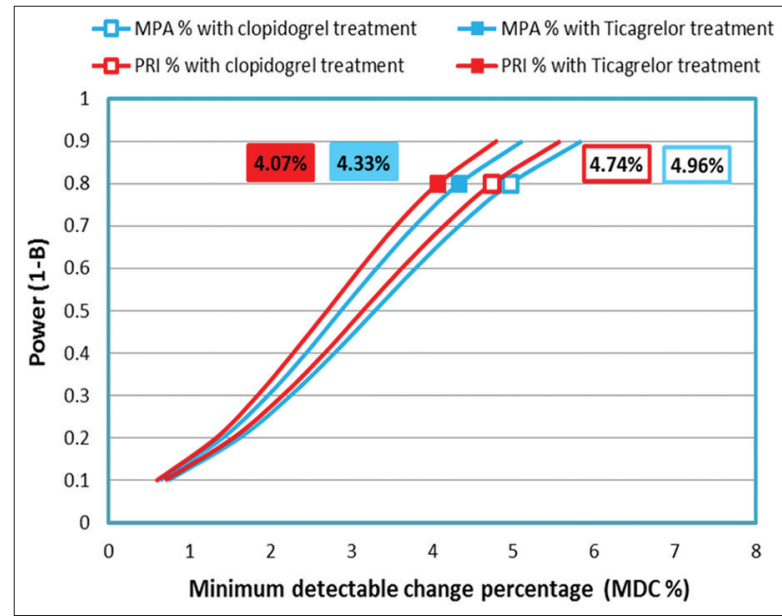

Fig. 3: Power analysis for the minimum detectable effect of clopidogrel treatment (75 mg daily) or ticagrelor treatment (90 mg twice daily) on maximal platelet aggregation percent and on platelet reactivity index percent after 2 weeks treatments.

Assuming alpha $=0.05$, beta $=0.2$, power $(1$-beta $)=0.8(80 \%)$, and sample size $=42$

Some patients after taking antiplatelet drugs will have high posttreatment platelet reactivity which is a better estimate of thrombotic risk than pre-treatment platelet reactivity [21]. Barragan et al. found that inhibition of platelet activity $<50 \%$ using PRIP is preferred to reduce the risk of stent thrombosis [16]. Other study found that the mortality rate in patients with an acute coronary syndrome has not significantly reduced with clopidogrel treatment [2], or with glycoprotein IIb/IIIa inhibitors treatment [22].

Many studies reported various limitations of clopidogrel therapy which include variable and irreversible platelet inhibition, slow onset of action, modest level of platelet inhibition, and considerably proportion of patients exhibiting limited response [23]. However, numerous strategies have been used to improve responses to clopidogrel, including increasing dosages or adding other agents [24].

The values of international normalization ratio (INR) in some patients were falsely impaired and increased due to the interference of antiphospholipid antibody with thromboplastins [25]. In addition, some drugs can form a complex with platelets and trigger immunemediated thrombocytopenia that enhances platelets destruction and suppresses platelets levels [26].

\section{CONCLUSION}

Ticagrelor a reversibly platelet $\mathrm{P}_{2} \mathrm{Y}_{12}$ receptor binding oral drug has more intense platelets inhibition than Clopidogrel, and so reduces the risks of ischemic events and mortality without increasing major bleeding, and it may use to overcomes the non-responsiveness to clopidogrel.

\section{ACKNOWLEDGMENTS}

I would like to thank the Department of Cardiology for assistance and to appreciate all the patients participated in this study. 


\section{SOURCES OF FUNDING}

There is no source of funding

\section{AUTHOR'S CONTRIBUTION}

The author Dr.Feryal Hashim Rada contributed to design the research idea, collect and analyze the data, write and redact the manuscript.

\section{CONFLICTS OF INTEREST}

There are no conflicts of interest to declare.

\section{REFERENCES}

1. Antithrombotic Trialists'(ATT) Collaboration, Baigent C, Blackwell L, Collins R, Emberson J, Godwin J, et al. Aspirin in the primary and secondary prevention of vascular disease: Collaborative metaanalysis of individual participant data from randomised trials. Lancet 2009;373:1849-60

2. Yusuf S, Zhao F, Mehta SR, Chrolavicius S, Tognoni G, Fox KK, et al. Effects of clopidogrel in addition to aspirin in patients with acute coronary syndromes without ST-segment elevation. N Engl J Med 2001;345:494-502

3. Patrono C, Baigent C, Hirsh J, Roth G. Antiplatelet drugs: American college of chest physicians evidence-based clinical practice guidelines ( $8^{\text {th }}$ edition). Chest 2008; 133:199S-233S.

4. Gurbel PA, Antonino MJ, Bliden KP, Dichiara J, Suarez TA, Singla A, et al. Platelet reactivity to adenosine diphosphate and long-term ischemic event occurrence following percutaneous coronary intervention: A potential antiplatelet therapeutic target. Platelets 2008;19:595-604.

5. Gurbel PA, Bliden KP, Butler K, Tantry US, Gesheff T, Wei C, et al. Randomized double-blind assessment of the ONSET and OFFSET of the antiplatelet effects of ticagrelor versus clopidogrel in patients with stable coronary artery disease: The ONSET/OFFSET study. Circulation 2009; $120: 2577-85$

6. Wiviott SD, Braunwald E, McCabe CH, Montalescot G, Ruzyllo W, Gottlieb S, et al. Prasugrel versus clopidogrel in patients with acute coronary syndromes. N Engl J Med 2007;357:2001-15.

7. Wallentin L, Becker RC, Budaj A, Cannon CP, Emanuelsson H, Held C, et al. Ticagrelor versus clopidogrel in patients with acute coronary syndromes. N Engl J Med 2009;361:1045-57.

8. Gurbel PA, Bliden KP, Hiatt BL, O'Connor CM. Clopidogrel for coronary stenting: Response variability, drug resistance, and the effect of pretreatment platelet reactivity. Circulation 2003;107:2908-13.

9. Bonello L, Camoin-Jau L, Arques S, Boyer C, Panagides D, Wittenberg $\mathrm{O}$, et al. Adjusted clopidogrel loading doses according to vasodilator-stimulated phosphoprotein phosphorylation index decrease rate of major adverse cardiovascular events in patients with clopidogrel resistance: A multicenter randomized prospective study. J Am Coll Cardiol 2008;51:1404-11.

10. Gurbel PA, Bliden KP, Butler K, Antonino MJ, Wei C, Teng R, et al. Response to ticagrelor in clopidogrel nonresponders and responders and effect of switching therapies: The RESPOND study. Circulation 2010;121:1188-99.

11. Steg PG, James S, Harrington RA, Ardissino D, Becker RC, Cannon CP, et al. Ticagrelor versus clopidogrel in patients with ST-elevation acute coronary syndromes intended for reperfusion with primary percutaneous coronary intervention: A Platelet inhibition and patient outcomes (PLATO) trial subgroup analysis. Circulation 2010;122:2131-41.

12. Husted S, van Giezen JJ. Ticagrelor: The first reversibly binding oral
P2Y12 receptor antagonist. Cardiovasc Ther 2009;27:259-74.

13. Cannon CP, Husted S, Harrington RA, Scirica BM, Emanuelsson H, Peters G, et al. Safety, tolerability, and initial efficacy of AZD6140, the first reversible oral adenosine diphosphate receptor antagonist, compared with clopidogrel, in patients with non-ST-segment elevation acute coronary syndrome: Primary results of the DISPERSE-2 trial. J Am Coll Cardiol 2007;50:1844-51

14. Cannon CP, Harrington RA, James S, Ardissino D, Becker RC, Emanuelsson $\mathrm{H}$, et al. Comparison of ticagrelor with clopidogrel in patients with a planned invasive strategy for acute coronary syndromes (PLATO): A randomised double-blind study. Lancet 2010;375:283-93.

15. Chan MY, Mahaffey KW, Sun LJ, Pieper KS, White HD, Aylward PE, et al. Prevalence, predictors, and impact of conservative medical management for patients with non-ST-segment elevation acute coronary syndromes who have angiographically documented significant coronary disease. JACC Cardiovasc Interv 2008;1:369-78.

16. Barragan P, Bouvier JL, Roquebert PO, Macaluso G, Commeau P, Comet $\mathrm{B}$, et al. Resistance to thienopyridines: Clinical detection of coronary stent thrombosis by monitoring of vasodilator-stimulated phosphoprotein phosphorylation. Catheter Cardiovasc Interv 2003;59:295-302.

17. Campo G, Valgimigli M, Gemmati D, Percoco G, Tognazzo S, Cicchitelli $\mathrm{G}$, et al. Value of platelet reactivity in predicting response to treatment and clinical outcome in patients undergoing primary coronary intervention: Insights into the STRATEGY study. J Am Coll Cardiol 2006; 48:2178-85.

18. Hochholzer W, Trenk D, Bestehorn HP, Fischer B, Valina CM, Ferenc $\mathrm{M}$, et al. Impact of the degree of peri-interventional platelet inhibition after loading with clopidogrel on early clinical outcome of elective coronary stent placement. J Am Coll Cardiol 2006;48:1742-50.

19. Massberg S, Grüner S, Konrad I, Garcia Arguinzonis MI, Eigenthaler M, Hemler K, et al. Enhanced in vivo platelet adhesion in vasodilator-stimulated phosphoprotein (VASP)-deficient mice. Blood 2004;103:136-42.

20. Aleil B, Ravanat C, Cazenave JP, Rochoux G, Heitz A, Gachet C, et al. Flow cytometric analysis of intraplatelet VASP phosphorylation for the detection of clopidogrel resistance in patients with ischemic cardiovascular diseases. J Thromb Haemost 2005;3:85-92.

21. Samara WM, Bliden KP, Tantry US, Gurbel PA. The difference between clopidogrel responsiveness and posttreatment platelet reactivity. Thromb Res 2005;115:89-94

22. Boersma E, Harrington RA, Moliterno DJ, White H, Théroux P, Van de Werf F, et al. Platelet glycoprotein IIb/IIIa inhibitors in acute coronary syndromes: A meta-analysis of all major randomised clinical trials. Lancet 2002;359:189-98.

23. Gurbel PA, Antonino MJ, Tantry US. Recent developments in clopidogrel pharmacology and their relation to clinical outcomes. Expert Opin Drug Metab Toxicol 2009;5:989-1004.

24. Jeong YH, Lee SW, Choi BR, Kim IS, Seo MK, Kwak CH, et al. Randomized comparison of adjunctive cilostazol versus high maintenance dose clopidogrel in patients with high post-treatment platelet reactivity: Results of the ACCEL-RESISTANCE (Adjunctive cilostazol versus high maintenance dose clopidogrel in patients with clopidogrel resistance) randomized study. J Am Coll Cardiol 2009;53:1101-9.

25. Al-Meman A. I-Stat, coaguchek XS plus, and hemochron versus reference laboratory INRS: Pharmacist-managed clinics. Int J Pharm Pharm Sci 2015;7:284-8.

26. Lee S, Chary M, Salehi I, Bansal R. Immune-mediated adalimumabinduced thrombocytopenia for the treatment of ulcerative colitis. Int $\mathrm{J}$ Pharm Pharm Sci 2015;7:456-8. 